LIBRES: Library and Information Science Research

Electronic Journal ISSN 1058-6768

1999 Volume 9 Issue 1; March 31.

Bi-annual LIBRE9N1

\title{
THE DEVELOPMENT OF ELECTRONIC PUBLICATION IN CHINA
}

\author{
Dr. Wenbo Kuang \\ School of Library and Information Science, \\ Wuhan University \\ Hubei China 430072 \\ wbkuang@hotmail.com
}

\begin{abstract}
The article discusses the current situation of electronic publication in China: its achievement and its problems. The author puts forward some proposals for developing electronic publications in this country.
\end{abstract}

Keywords: electronic publishing, Internet publishing, China

\section{INTRODUCTION}

The author is an advanced researcher of electronic publishing technology at Wuhan University, a famous University that is the birthplace of the first electronic publication in China.

A number of relevant articles and information about electronic publishing and publications in China since 1990 were reviewed before this author set pen to paper.

\section{BACKGROUND}

Nowadays, books are an 'everyday' phenomenon with which virtually everyone is familiar. Indeed, these entities form an important aspect of almost every human culture. Books include publication and electronic publication today.

Electronic publications are the publications which store digitized information on optical or magnetic media. These media must be read by computers or analogous equipment. The media are relatively small and light but they can hold a vast amount of information and the 
information can last long time. Multimedia and interactive electronic publications can be retrieved conveniently. The information on electronic publications can be refreshed, edited, transferred, communicated by the Internet quickly.

Electronic publications are speedily accessed, provide retrieval accuracy, interactivity, and flexibility. Electronic publications spell a great impact on the social culture, science and education of the global community.

\section{ELECTRONIC PUBLISHING IN CHINA}

China started its research and development of CD-ROM technologies in the late 1970's. China's first optical recording and reading system was developed in 1985. The Internet was introduced in China in 1987. Professor Guangzuo Chen created the first electronic publication-The relation history of Kuomintang and Chinese Communist Party -at Wuhan University in 1991. Now China is becoming one of the electronic publishing centers in Asia.

China has produced many CD-ROM products since 1993. In 1997 there were 28 CD-ROM product lines and $22 \mathrm{CD}-\mathrm{ROM}$ reproduction factories in China. The earlier CD-ROM electronic publications, were electronic journals, patent and law database. Now electronic publication has spread to culture, education, travel and the entertainment field. There are now more than 36 electronic publishing houses and more than 100 production companies. They published 1025 kinds of CD-ROM electronic publications, totaling 7,910,950 CD-ROM discs in 1997. Electronic publication is still growing at the rate of more than $200 \%$ per year in China.

Furthermore, electronic publications, which are transmitted by the Internet, called Internet publications, are growing fast too. In 1998 there were more than 300 Chinese electronic newspapers and periodicals, transmitted by Internet in China.

Chinese technicians and engineers have mastered many technologies for developing electronic publications, including Internet publications. For example, the Chinese characters coding and identification technology, information compression and storage technology, Compact Disc chisel and reproduction technology, Internet technology, etc, have been successfully mastered by the growing number of Chinese electronic publications creators and producers.

The conditions for developing electronic publications are improving rapidly in China. There are more than 10 million computers in China, and this number is growing at the rate of $66 \%$ per year.

The telecommunications industry of China is developing rapidly too. In 1998 there were 0.125 billion telephones in China by 1998. The rate of telephone popularization is 12.9 per 100 person in the whole country, it is 29 per 100 person in cities. The popularity of the Internet was gradual in China. Furthermore, the marketplace of electronic publications is vast. The government of China thinks much of the management and development of 
electronic publications. It released "The temporary decree for electronic publications" in 1996. The government of China bans the pirating of electronic publication too.

\section{LIMITATIONS TO THE DEVELOPMENT OF ELECTRONIC PUBLICATION IN CHINA}

Electronic publications in China are mainly CD-ROM products. Internet publications, the electronic publications that publish through Internet, are relatively less than the CD-ROM products.

Electronic publishing houses often lack the abilities to exploit and produce electronic publications, while the computer companies often lack the right of electronic publishing. The government of China just permits the 'formal' presses, which are censored strictly to develop electronic publication. But not all the 'formal' presses possess the essential conditions, such as capital, technicians, artists, etc, to create electronic publication. Many computer firms possess the conditions to develop electronic publication, but the government forbids them to produce electronic publication for the political cause. This is a strange phenomenon in the electronic publishing field in China.

China lacks enough mechanics, artists and managers for creating electronic publications. There are 6,763 Chinese characters in a standard database (GB Chinese characters database). But the amount of Chinese characters in the Chinese characters standard database is too insufficient to publish some large-scale electronic publications. For example, "25 history" records 13,966 Chinese characters; "Chinese great dictionary" embodies 22,729 Chinese characters.

Lack of finance in the electronic publishing field is another major obstacle for developing electronic publication in China.

\section{A FUTURE WAY TO DEVELOPING ELECTRONIC PUBLICATION IN CHINA}

The government of China should support the electronic publishing industry in policy and finance. As mentioned above, financial shortage is a barrier to the development of electronic publications. Great advances can be foreseen if the government is committed to formulate favorable policies in this respect and to subsidize electronic publishers as necessary.

The capacity of mass production is the key factor of productivity. In order to achieve this, the government's support is very helpful. Further, stricter measures should be adopted to protect the copyright of electronic publications.

Electronic publishing houses should associate with computer firms and telecommunication services when they want to create and produce electronic publications, especially when they desire to develop Internet publications. In China the computer companies often possess the technologies, facilities, funds; while the presses usually possess abundant publishing resources, editors with experience, the managers who comprehend the news and 
publishing decrees. The telecommunication services control the Internet in China. So, if any corporations want to develop Internet publications in China, the participation of the telecommunications industry is necessary.

The electronic presses in Mainland China can join with the ones in Hongkong and Taiwan. The electronic publishing industry in Hongkong and Taiwan is growing fast too. The managers of electronic publishing houses in the two areas often pay attention to marketing when they sell their products.

The creation and production of electronic publications, especially Internet publications, requires computer experts, information experts, editors and managers with experience artists with computer skills. So their collaboration is necessary, especially in China. China lacks abundant electronic publishing professionals.

Standards have an important role to play within all areas of human endeavor. Of course, they assume particular importance within the creation, production and distribution of electronic publications (especially the Internet publications). These are internationally defined standards (such as those agreed by the International Standard Organization and related bodies) or they may be de facto standards (such as Adobe's PDF files for electronic

publishing). Undoubtedly, one of the most useful developments in the electronic publishing arena has been the introduction of SGML and its associated derivatives. The administration of electronic publishing in China should formulate standards, which can meet the requirement of the Chinese characters electronic publishing.

\section{CONCLUSION}

Currently, four basic types of media are popular use for the publication of documents and books: paper, computer discs, CD-ROM and computer networks. But electronic publication, mainly in CD-ROM and Internet publication, is growing fast wherever in the world or in China. Electronic publications will play a more and more important role in the human culture field.

\section{References}

1. Xiaomao Mao. The China electronic publishers shoulder heavy responsibilities. National New Bibliography, 1997(3)

2. Zhongyuan Si. The actuality and prospect of China electronic Publishing. Chinese Youth Research, 1997(3)

3. Haibo xu. The actuality and future trend of electronic publications. News and Communication Research, 1996(1)

4. Lin An. The development of electronic publication. News and Publishing Guide, 1996(5) 
This document may be circulated freely with the following statement included in its entirety:

Copyright 1999.

This article was originally published in LIBRES: Library and Information Science Electronic Journal_(ISSN 1058-6768) March 31, 1999

Volume 9 Issue 1.

For any commercial use, or publication (including electronic journals), you must obtain the permission of the author.

Dr. Wenbo Kuang

School of Library and Information Science, Wuhan University

Hubei China 430072

wbkuang@hotmail.com

To subscribe to LIBRES send e-mail message to listproc@info.curtin.edu.au

with the text:

subscribe libres [your first name] [your last name]

Return to Libre9n1 Contents

Return to Libres Home Page

CRICOS provider code: 00301J 